\title{
Cost of Total Parenteral Nutrition Services at the Ministry of Health, Saudi Arabia
}

\author{
Yousef Ahmed Alomi ${ }^{1 * *}$ (D), Aisha Omar Fallatah ${ }^{2}$, Amjad Ahmad AL qahtani ${ }^{3}$, Nesreen Al-Shubbar ${ }^{4}$, \\ Maha F Al-Yahya ${ }^{5}$, Estiqlal Hussain Al-Smail ${ }^{6}$ \\ ${ }^{I}$ The Past General Manager of General Administration of Pharmaceutical Care and Head, National Clinical pharmacy \\ and Pharmacy Practice and Pharmacy $R$ and D Administration, MOH, Riyadh, KSA. \\ ${ }^{2}$ Supervisor of IV Admixture Services, King Salman Hospital, MOH, Riyadh, KSA. \\ ${ }^{3}$ Clinical Pharmacy Staff, General Administration of Pharmaceutical Care, MOH, Riyadh, KSA. \\ ${ }^{4}$ Head, Pharmacy services, King Salman Hospital, MOH, Riyadh, KSA. \\ ${ }^{5}$ Former Head, Pharmacy services, King Salman Hospital, MOH, Riyadh, KSA. \\ ${ }^{6}$ TPN Pharmacist, Pharmacy services, King Salman Hospital, MOH, Riyadh, KSA.
}

\begin{abstract}
Objectives: The estimation of cost of total parenteral nutrition (TPN) is a part of the pharmacoeconomic program at the Ministry of Health ( $\mathrm{MOH}$ ), Saudi Arabia. In this study, we explored the cost analysis of TPN services by using American Model with local cost. Methods: Simulation was performed for all 6 months of TPN services for neonate, pediatric and adult patients. King Salman Hospital in Riyadh, Saudi Arabia was chosen as the study site; it has 300 beds. The physician or the pharmacist prescribed TPN to their patients. The pharmacist reviews and prepares TPN. The nurse administers TPN and follows up with the doctor or the pharmacist. TPN was prepared through sterile 797 standards and automated compounding facilities. The costing was derived from $\mathrm{MOH}$ information database. The cost was calculated based on the variable expenses including personal cost, material cost and supply cost. Fixed costs included direct cost, non-salary cost and overhead cost. All costs were estimated in US dollar currency and local prices. Results: A total number of 112 patients were prescribed with (1631) TPN orders; the total volume of TPN was $619,161.90 \mathrm{~mL}$. Of these, 103 (91.96\%), 6 (5.36\%) and $3(2.68 \%)$ were prescribed for neonatal, adult and pediatric patients, respectively. Of those with TPN orders, $1484(90.99 \%), 108(6.62 \%)$ and 39 (2.39\%) were prescribed for neonatal, adult and pediatric patients, respectively. The total average number of orders per day was 4.47 . Of those, $4.07,0.3$ and 0.11 was for neonatal, adult and pediatric patients, respectively. The average duration of TPN for adults, neonatal and pediatric patients was 18 , 14.4 and 13 days, respectively. The total average direct cost for active ingredient in the TPN was 61.81 USD. Of those, 38.54 USD (62.35\%), 16.63 USD (26.91\%) and 6.64 USD (10.74\%) was for pediatric, adult and neonatal patients. The estimated cost of TPN services for neonatal, adult and pediatric patients was 863.74 USD, 691.3 USD and 618.16 USD per day, respectively. The total annual and daily estimated expenditures of TPN orders were 629,865.02 USD and 212.22 USD; 44,795.24 USD and 207.39 USD; and 5,303.77 USD and 68.00 USD respectively for neonatal, adult and pediatric patients. The total annual and daily estimated cost were 314,764.70 USD and 3,055.97 USD; 22,398.12 USD and 3,733.02 USD; and 2,652.00 USD and 884.00 USD respectively for neonatal, adult and pediatric patients. Conclusion: In this study, we performed cost-estimation of the TPN in Saudi Arabia. This is the first study at $\mathrm{MOH}$ in Saudi Arabia. It is an essential basic element of pharmacoeconomic program and cost analysis of TPN-related healthcare services.

Key words: Cost, Total Parenteral Nutrition, Ministry of Health, Saudi Arabia.
\end{abstract}

Received: 07-10-2018; Accepted: 20-12-2018

*Correspondence to:

Dr. Yousef Ahmed Alomi

The Former General Manager of Genera Administration of Pharmaceutical Care Head, National Clinical Pharmacy and Pharmacy Practice, Former Head, Pharmacy R and D Administration, Ministry of Health, P.O.BOX 100, Riyadh 11392, Riyadh, SAUDI ARABIA. Phone no: +966504417712 Email: yalomi@gmail.com

DOI: 10.5530/ijpcs.2019.8.8

Copyright: ( $)$ the author(s),publisher and licensee International Journal of Pharmacology and Clinical Sciences. This is an open-access article distributed under the terms of the Creative Commons Attribution Non-Commercial License, which permits unrestricted noncommercial use, distribution, and reproduction in any medium, provided the original work is properly cited.

This is an open access article distributed under the terms of the Creative Commons Attribution-NonCommercial-ShareAlike 4.0 License

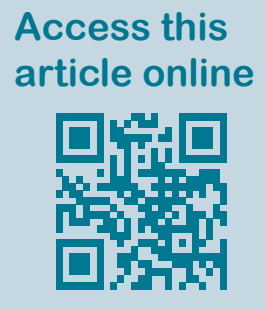

www.ijpcs.net 


\section{INTRODUCTION}

Total parenteral nutrition (TPN) is the critical element of nutritional care for neonatal, pediatric and adult patients. TPN is indicated for someone who cannot or should not ingest nutrients through their regular oral pathway. Over the past few years, the American Society of Parenteral and Enteral Nutrition (ASPEN) releases several guidelines for the assessment, prescription, preparation, administration and follow-up of the TPN with an emphasis on patient safety. ${ }^{[1-3]}$ The ASPEN published general guidelines to assure patient safety and prevent nutrition-related problems to avoid unnecessary and additional economic burden on the healthcare system. ${ }^{[4]}$ The pharmacist plays an excellent role in in this field. ${ }^{[5]}$ Several studies have shown their role in the practice of parenteral nutrition at the Ministry of Health (MOH) hospitals. ${ }^{[6-8]}$ However, to the best of our knowledge, the cost analysis of TPN services have not yet been analyzed in Saudi Arabia. Several groups of scientists have explored the cost of TPN at the hospital or during home healthcare, for neonatal or adult patients, with two or three in one mixing system bags of TPN. Curtas et al. assessed time and costs associated with the management of TPN patients after discharge from the hospital using a cost-identification analysis of 24 different factors. ${ }^{[9]}$ The nutrition support team members kept daily activity logs over a 2-week period. This computes to a total annual personnel cost of 168,482 USD (1982 USD per patient). If the cost of furnishings and space are also included, then the overall cost of all resources was 175,989 USD per year or 2070 USD per patien. ${ }^{[9]}$ A study by Menne et al. in 2008 aimed to evaluate the overall cost of Parenteral nutrition (PN) using the three-compartment bag versus standard multi-bottle system. The overall costs of hospital PN were calculated from the expenditures (solutions, consumable items and staff costs). Standard treatment algorithms of a 10-day course of PN for a standard 70-kg patient were specified for both systems. The daily total cost of the three-compartment bag system was $€ 42.26$ per patient, whereas the total cost of the separate bottle system was $€ 51.62$, resulting in a cost saving of $€ 9.36$ per patient with the three-compartment bag system. For 10 days of treatment, PN costs $€ 422.51$ per patient for the three-compartment system versus $€ 516.16$ for the multi-bottle system. ${ }^{[10]}$

Petrelli et al. ${ }^{[11]}$ published a study aimed to assess the total cost and benefits of TPN bags manufactured by the hospital pharmacy in comparison with supplemented TPN bags manufactured by commercial firms. They prepared 8232 bags for patients in 2003: 6080 bags for inpatients and 2152 bags for outpatients. The total cost of one of their bags was $€ 37.64,71 \%$ of the cost was for the raw materials. ${ }^{[1]]} \mathrm{Al}$ Batania et al.$^{[12]}$ conducted a study to evaluate the costs, complications and outcomes of patients treated with TPN in Universiti Sains Malaysia Hospital (HUSM), Malaysia. They evaluated the retrospective data obtained from the patient's medical records and 215 TPN cases from 2003 to 2005. The average cost of TPN in neonatal, pediatric and adult patients was $€ 20.45 \pm 9.60, € 43.82 \pm 25.25$ and $€ 83.06 \pm 21.50 .{ }^{[12]}$ Walter et al. conducted a study to create a model to assess the total costs of PN therapy for neonates, infants and children using formulations manufactured in the hospital, either in a hospital pharmacy or in the ward.

Face-to-face and telephonic interviews were conducted in 12 hospitals among four European countries (Belgium, France, Germany and the UK) to collect information on resources utilized to compound $\mathrm{PN}$, including nutrients, staff time and equipment cost and supplies. The average cost per bag for infants $<2$ years was $€ 84.52$ ( $€ 74.65$ in Belgium, $€ 83.84$ in France, $€ 92.70$ in Germany and $€ 60.26$ in the UK). The average cost per bag for children within 2-18 years of age was $€ 118.02$ (€93.85 in Belgium, €121.35 in France, $€ 124.54$ in Germany and $€ 79.56$ in the UK), of which $63 \%$ is attributable to the nutrients and $28 \%$ to the wages. In the study; it has been concluded that the PN costs differ among countries and a significant proportion of the difference was due to the staff time. [13] To address the growing importance of costs in intensive care, Gamsjäger et al. investigated, through retrospective analysis, whether relevant differences between individualized admixtures and standard solutions in terms of costs can be found. The analysis was performed in university-affiliated intensive care unit on fifty consecutively admitted pediatric patients requiring $\mathrm{PN}$. The mean actual costs of individualized admixtures was $€ 81.78 \pm 16.33$ per patient. ${ }^{[14]}$ Based on best of our knowledge; there is no study existed at Saudi Arabia, the Gulf, or Middle Eastern countries. Therefore, the goal of this study was to explore the cost analysis of TPN services at the public hospital in Riyadh city, Saudi Arabia.

\section{METHOD}

We simulated the data of 6 months of 2015 related to TPN services for neonatal, pediatric and adult patients. The hospital in Riyadh, Saudi Arabia has 280 beds. 
It has several specialties including adults endocrinology, adults nephrology, pediatrics, adult's cardiology, adults internal medicine, adults surgery, adults critical care, NICU, PICU, obstetrics and gynecology. The hospital has ambulatory care services and emergency services with above specialties. In addition, the hospital is accredited to pharmaceutical services including inpatient pharmacy, ambulatory care pharmacy, TPN services, drug information services and computerized physician order entry system at inpatient and outpatient units. In 2009, the pharmacy services established TPN services starting from physician's prescription; the pharmacist reviews the order and prepares and dispenses the order; the nurse administers the preparation to the patients. TPN is prepared through sterile 797 standards and automated compounding facilities. The cost of TPN in MOH hospitals calculated by counting the personal cost including the cost of doctor, pharmacist and pharmacy technician per hour and the cost calculation based on preparation time of each TPN bag. Then, the total prices of the overhead cost for the bed and all machines will be used to estimate the cost of TPN service. Also, the cost of purchased materials and supplies plus non-salary cost. The authors calculated the purchased cost for the direct cost for TPN preparation and lipid as 2 in 1 mixing system TPN type. They also calculated the purchased prices of TPN lab tests and average length of stay of neonatal, pediatric and adult patients. The medication prices considered from Gulf Corporation Council Countries (GCCC) tender prices database version 36. The authors used Baxa system (ME2400) machines to calculate all the active components of TPN preparation orders; it was the average cost of preparation for 6 months' of TPN preparations in 2015. All costs were depicted in US dollar currency. One-way sensitivity analysis was conducted for a list of discount prices and variety of wage cost with $10-20 \%$.

\section{RESULTS}

A total number of 112 patients were prescribed with TPN (1631) orders; the total volume of TPN was 619, $161.90 \mathrm{~mL}$. Of these patients, 103 (91.96\%), 6 (5.36\%) and $3(2.68 \%)$ were neonatal, adult and pediatric patients, respectively. Of the TPN orders, 1484 (90.99\%), 108 (6.62\%) and 39 (2.39\%) orders were for neonatal, adult and pediatric patients, respectively. Of the total volume of TPN, 378,741.90 mL (61.17\%); 196, $880 \mathrm{~mL}$ (31.8\%); and 196,880 mL (31.8\%) was for neonatal, adult and pediatric patients, respectively. The total average number of orders per day was 4.47.
Of these, 4.07, 0.3 and 0.11) was for neonatal, adult and pediatric patients, respectively. The average duration of TPN treatment for adult, neonatal and pediatric patients was 1814.4 and 13 days. The total average volume per order was 3,194.59 mL; of this $1,822.96 \mathrm{~mL}$ (57.06\%); $1,116.41 \mathrm{~mL}$ (34.95\%); and $255.22 \mathrm{~mL}$ (7.99\%) was for adult, pediatric and neonatal patients, respectively. The total direct cost of TPN's active ingredient was 13,152.53 USD. Of this, 9, 853.45 USD (74.92\%); 1,796.16 USD (13.66\%); and 1,502.92 USD (11.43\%) was for neonatal, adult and pediatric patients, respectively. The total average direct cost for TPN's active ingredient was 61.81 USD. Of this, 38.54 USD (62.35\%), 16.63 (26.91\%) and $6.64(10.74 \%)$ was for pediatric, adult and neonatal patients (Table 1). The estimated cost of TPN services for neonatal patients was 863.74 USD. Of this, the majority of cost came from the overhead cost ( 387.83 USD (44.90\%)) followed by the direct cost (196.72 USD $(22.78 \%))$ and personal cost (153.23 USD (17.74\%)). The estimated cost of TPN services for adult patients was 691.3 USD per day. Of this, the majority of cost came from the overhead cost (279.83 USD (40.48\%)) followed by the direct cost (213.43 USD (30.87\%)) and material and supply cost (108.3 USD (15.67\%)). The estimated cost of TPN services for pediatric patients was 618.16 USD per day. Of this, most of the cost came from the direct cost (230.43 USD (37.28\%)), followed by the personal cost (142.61 USD (23.07\%)) and the overhead cost (121.17 USD (19.6\%)) (Table 2). The total annual and daily estimated expenditure of TPN orders were 629,865.02 USD and 212.22 USD; 44,795.24 USD and 207.39 USD; and 5,303.77 USD and 68.00 USD respectively for neonatal, adult and pediatric patients (Table 3). The total annual and daily estimated cost of TPN were 314,764.70 USD and 3,055.97 USD; 22,398.12 USD and 3,733.02 USD; and 2,652.00 USD and 884.00 USD respectively for neonatal, adult and pediatric patients (Table 4).

\section{DISCUSSION}

In the past 5 years, the general administration of pharmaceutical care at the $\mathrm{MOH}$ implemented several pharmacy practice program including total parenteral nutrients for neonates, pediatrics and adults. ${ }^{[15-16]}$ During this period, we conducted a general survey of PN practice in Saudi Arabia. ${ }^{[7,17]}$ The survey explored several elements in detail except for the cost analysis of TPN. Therefore, in this study, we aimed to explore the cost analysis of TPN services at a public hospital in the Ministry of Health, Saudi Arabia. Our results showed the most of the patients were neonates because of the 
Alomi, et al.: Cost of TPN at the Ministry of Health, Saudi Arabia

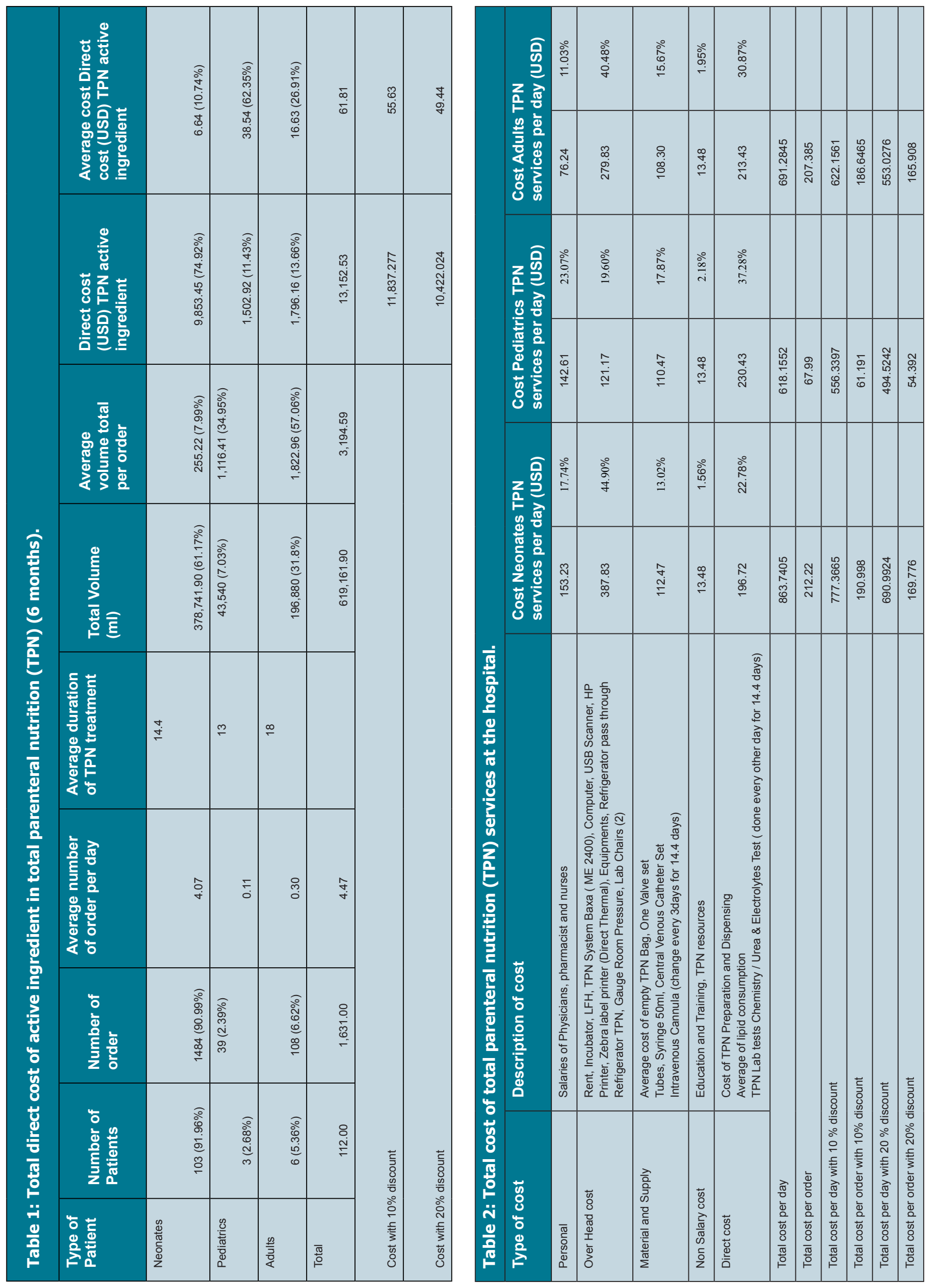




\begin{tabular}{|c|c|c|c|c|c|c|c|c|c|}
\hline \multirow[b]{2}{*}{ Type of cost } & \multicolumn{3}{|c|}{$\begin{array}{l}\text { Cost of Neonates TPN orders } \\
\text { (USD) }\end{array}$} & \multicolumn{3}{|c|}{$\begin{array}{l}\text { Cost of Pediatrics TPN orders } \\
\text { (USD) }\end{array}$} & \multicolumn{3}{|c|}{ Cost Adults TPN orders (USD) } \\
\hline & $\begin{array}{l}\text { Cost per } \\
\text { day }\end{array}$ & $\begin{array}{l}\text { Cost per } \\
6 \text { months }\end{array}$ & $\begin{array}{l}\text { Annual } \\
\text { cost }\end{array}$ & $\begin{array}{l}\text { Cost } \\
\text { per day }\end{array}$ & $\begin{array}{l}\text { Cost per } 6 \\
\text { months }\end{array}$ & $\begin{array}{l}\text { Annual } \\
\text { cost }\end{array}$ & $\begin{array}{l}\text { Cost } \\
\text { per day }\end{array}$ & $\begin{array}{l}\text { Cost per } \\
6 \text { months }\end{array}$ & $\begin{array}{l}\text { Annua } \\
\text { cost }\end{array}$ \\
\hline Personal & 37.65 & $55,870.59$ & $111,741.19$ & 15.69 & 611.80 & $1,223.59$ & 22.87 & $2,470.18$ & $4,940.35$ \\
\hline Over Head cost & 95.29 & $141,410.25$ & $282,820.50$ & 13.33 & 519.82 & $1,039.64$ & 83.95 & $9,066.49$ & $18,132.98$ \\
\hline Material and Supply & 27.63 & $41,008.72$ & $82,017.43$ & 12.15 & 473.92 & 947.83 & 32.49 & $3,508.92$ & $7,017.84$ \\
\hline Non Salary cost & 3.31 & $4,915.07$ & $9,830.13$ & 1.48 & 57.83 & 115.66 & 4.04 & 436.75 & 873.50 \\
\hline Direct cost & 48.33 & $71,727.88$ & $143,455.76$ & 25.35 & 988.54 & $1,977.09$ & 64.03 & $6,915.13$ & $13,830.2$ \\
\hline Total Cost & 212.22 & $314,932.51$ & $629,865.02$ & 68.00 & $2,651.89$ & $5,303.77$ & 207.39 & $22,397.62$ & $44,795.2$ \\
\hline Total cost with $10 \%$ discount & 190.998 & $283,439.26$ & $566,878.52$ & 61.191 & $2,386.70$ & $4,773.39$ & 186.6465 & $20,157.86$ & $40,315.7$ \\
\hline Total cost with $20 \%$ discount & 169.776 & $251,946.01$ & $503,892.02$ & 54.392 & $2,121.51$ & $4,243.02$ & 165.908 & $16,126.29$ & $32,252.5$ \\
\hline
\end{tabular}

\begin{tabular}{|l|c|c|c|c|c|c|c|c|c|}
\hline \multicolumn{2}{|l|}{ Table 4: Total cost of total parenteral nutrition (TPN) per patient. } \\
\hline & \multicolumn{2}{|l|}{$\begin{array}{l}\text { Cost of Neonates TPN patients } \\
\text { (USD) }\end{array}$} & \multicolumn{2}{l|}{$\begin{array}{l}\text { Cost of Pediatrics TPN } \\
\text { patients (USD) }\end{array}$} & \multicolumn{3}{l|}{$\begin{array}{l}\text { Cost Adults TPN patients } \\
\text { (USD) }\end{array}$} \\
\hline Type of cost & $\begin{array}{l}\text { Cost } \\
\text { per day }\end{array}$ & $\begin{array}{l}\text { Cost per } \\
\text { patient }\end{array}$ & $\begin{array}{l}\text { Patient } \\
\text { Annual } \\
\text { cost }\end{array}$ & $\begin{array}{l}\text { Cost } \\
\text { per day }\end{array}$ & $\begin{array}{l}\text { Cost } \\
\text { per } \\
\text { patient }\end{array}$ & $\begin{array}{l}\text { Annual } \\
\text { cost }\end{array}$ & $\begin{array}{l}\text { Cost per } \\
\text { day }\end{array}$ & $\begin{array}{l}\text { Cost } \\
\text { per } \\
\text { patient }\end{array}$ & $\begin{array}{l}\text { Annual } \\
\text { cost }\end{array}$ \\
\hline Personal & 37.65 & 542.16 & $55,842.48$ & 15.69 & 203.97 & 611.91 & 22.87 & 411.66 & $2,469.96$ \\
\hline Over Head cost & 95.29 & $1,372.18$ & $141,334.13$ & 13.33 & 173.29 & 519.87 & 83.95 & $1,511.10$ & $9,066.60$ \\
\hline Material and Supply & 27.63 & 397.87 & $40,980.82$ & 12.15 & 157.95 & 473.85 & 32.49 & 584.82 & $3,508.92$ \\
\hline Non Salary cost & 3.31 & 47.66 & $4,909.39$ & 1.48 & 19.24 & 57.72 & 4.04 & 72.72 & 436.32 \\
\hline Direct cost & 48.33 & 695.95 & $71,683.06$ & 25.35 & 329.55 & 988.65 & 64.03 & $1,152.54$ & $6,915.24$ \\
\hline Total Cost & 212.22 & $3,055.97$ & $314,764.70$ & 68.00 & 884.00 & $2,652.00$ & 207.39 & $3,733.02$ & $22,398.12$ \\
\hline Total cost with 10\% discount & 190.998 & $2,750.37$ & $283,288.23$ & 61.191 & 795.60 & $2,386.80$ & 186.6465 & $3,359.72$ & $20,158.31$ \\
\hline Total cost with 20\% discount & 169.776 & $2,444.78$ & $251,811.76$ & 54.392 & 707.20 & $2,121.60$ & 165.908 & $2,986.42$ & $17,918.50$ \\
\hline
\end{tabular}

Neonates duration treatment: 14.4 days, Pediatrics duration treatment: 13 days, Adults duration treatment: 18 days

high demand for neonatal critical care of TPN services. Therefore, neonatal patients were found to benefit more than adult and pediatric patients. However, TPN has not reduced the mortality or morbidity; it increases the body weight of neonatal patients. ${ }^{[18]}$ The results showed a high cost of neonatal TPN with complete services or TPN orders or TPN patients and they are more than adults and pediatrics because high consumption of raw materials and had a good number of patients and TPN orders. While the cost of TPN for adult and pediatric patients was lower than that of neonatal patients because of the less consumption of active ingredients. Moreover, the personal cost of adults' TPN was less than neonatal TPN as the pharmacist is responsible for the adults' TPN services. Future studies should focus on the cost of TPN for adult and pediatric patients. The finding showed a high cost of TPN services that need to increase the number of clinical pharmacists to set up the TPN guidelines and implement the medications usage evaluation to control the incremental cost. In this study, the costs of TPN for neonatal, adult and pediatric patients were found to be more than that reported in other studies. This is related to the usage of new automated compounding services in this study, whereas most of the previous studies did not use this service. Some studies may be used nutritionist or nurses for TPN services were less salary than the pharmacist and subsequently lower TPN cost. Also, the long time frame between our study and previous investigations lead to increase the materials prices. ${ }^{[9-14]}$ This showed that the cost of pediatric TPN cost was lower than what had been reported in other studies because of number pediatrics patient in our study were few and subsequently underestimated the real pediatrics TPN cost. ${ }^{[13-14]}$ The average duration of TPN for neonatal patients was found to be less than that for adult patients and it was as same as pediatric patients; that's related to the providing a good neonatal TPN service and utilized expert physician with TPN while the adults TPN services not similar to them. The daily cost of adults' TPN was more than that for neonatal and pediatric patients due to the longer duration of treatment. This finding is more than what has been reported in other studies, which may be due to the TPN guidelines and 
health insurance control adherence implemented in other studies. ${ }^{[10]}$ The cost analysis of neonatal patients was clear, which can be utilized in the medical practice, whereas the cost analysis for adult and pediatric patients need additional studies to validate the results with more patients and TPN orders. This was the first study in the Kingdom of Saudi Arabia, the Gulf and Middle Eastern countries. More studies regarding cost analysis for clinical pharmacy services are needed to meet the updated pharmacy strategic plan of Saudi vision 2030 in Saudi Arabia. ${ }^{[19]}$

\section{Limitations}

Despite new information about TPN cost calculations in Saudi Arabia, the study had several limitations including the prices of TPN material which changed annually with general tender; bag wastage of TPN was not calculated.

\section{CONCLUSION}

This is the first study to calculate the cost of TPN services and preparations in Saudi Arabia, the Gulf and Middle Eastern countries. The results assess all the healthcare professionals to measure cost efficiency of the nutrition support program based on the local cost. The TPN preparation cost should be updated regularly.

\section{ACKNOWLEDGMENT}

None.

\section{CONFLICT OF INTEREST}

None.

\section{ABBREVIATIONS}

KSA: Kingdom of Saudi Arabia; MOH: Ministry of Health; CBAHI: Saudi Central Board for Accreditation of Healthcare Institutions; USA: United States of America.

\section{ORCID ID}

Yousef Ahmed Alomi (D) https://orcid.org/0000-00031381-628X

\section{REFERENCES}

1. Directors ASPENB, Jacobs DO, Helton S. Guidelines for the Use of Parenteral and Enteral Nutrition in Adult and Pediatric Patients. J Parenter Enter Nutr. 2002;26(1_suppl):1SA-138SA.

2. Malone A. Clinical Guidelines from the American Society for Parenteral and Enteral Nutrition. J Infus Nurs. 2014;37(3):179-84.

3. Boullata JI, Gilbert K, Sacks G, Labossiere RJ, Crill C, Goday P, et al. A.S.P.E.N. Clinical guidelines: Parenteral nutrition ordering, order review, compounding, labeling and dispensing. J Parenter Enter Nutr. 2014;38(3):334-77.

4. Boullata JI, Carrera AL, Harvey L, Escuro AA, Hudson L, Mays A, et al. ASPEN Safe Practices for Enteral Nutrition Therapy. J Parenter Enter Nutr. 2017;41(1):15-103.

5. Alomi YA, Fallatah AO. Economics outcomes of pharmacist managed neonatal total parenteral nutrition services at Ministry of Health in Saudi Arabia. Value Heal. 2017;20(5):A42-A42.

6. Alomi YA, Aljudaibi SM. National Survey of Total Parenteral Nutrition Practice in Saudi Ara-bia: Dispensing and Administration at $\mathrm{MOH}$ Hospitals. EC Nutr. 2016;3(6):748-56.

7. Alomi YA, Aljudaibi SM. National Survey of Total Parentral Nutrition Practice in Saudi Arabia: Drug Monitoring and Patient Education at MOH Hospitals. EC Nutr. 2016;4:784-92.

8. Alomi YA, Fallatah AO. Cost Avoidance Of Pharmacist Running Pediatrics Total Parenteral Nutrition Services At Ministry Of Health In Saudi Arabia. Value Heal. 2016;19(7):A461.

9. Curtas S, Hariri R, Steiger E. Case Management in Home Total Parenteral Nutrition: A Cost-Identification Analysis. J Parenter Enter Nutr. 1996;20(2):113-9.

10. Menne R, Adolph M, Brock E, Schneider H, Senkal M. Cost Analysis of Parenteral Nutrition Regimens in the Intensive Care Unit: ThreeCompartment Bag System vs Multibottle System. J Parenter Enter Nutr. 2008;32(6):606-12.

11. Petrelli MD, Nicolai E, Tucci A, Giambenedetti M, Taus M, Busni D, et al. Total parenteral nutrition: Economic investigations comparing hospital prepared nutritional bags versus similar bags prepared by the pharmaceutical industry. Riv Ital di Nutr Parenter ed Enterale. 2004;22(4):186-92.

12. Batani R Al, Abdullah DC, Bahari MB. Evaluation of the total parenteral nutrition service at Universiti Sains Malaysia Hospital. E Spen Eur E J Clin Nutr Metab. 2007;2(6):e111-5.

13. Walter E, Liu FX, Maton P, Storme T, Perrinet M, von Delft O, et al. Cost analysis of neonatal and pediatric parenteral nutrition in Europe: a multicountry study. Eur J Clin Nutr. 2012;66(5):639-44.

14. Storme T, Perrinet M, Delft OV, et al. Cost analysis of neonatal and pediatric parenteral nutrition in Europe: a. Pediatr Crit Care Med. 2009;10(2):163-5.

15. Alomi YA. National Pharmacy Practice Programs at Ministry of Health in Saudi Arabia. J Pharm Pharm Scien. 2015;1(2):17-8.

16. Alomi YA. National Total Parenteral Nutrition Program at $\mathrm{MOH}$ in Saudi Arabia. EC Nutr. 2016;3:697-9.

17. Alomi YA, Ajudaibi SM. National Survey of Total Parenteral Nutrition Practice in Saudi Arabia: Dispensing and Administration at $\mathrm{MOH}$ Hospitals. EC Nutr. 2016;(3.6):748-56.

18. Heyland DK, Montalvo M, MacDonald S, Keefe L, Su XY, Drover JW. Total parenteral nutrition in the surgical patient: a meta-analysis. Can J Surg J Can Chir. 2001;44(2):102-11.

19. Alomi YA, Alghamdi SJ, Alattyh RA, Elshenawy RA. The Evaluation of Pharmacy Strategic Plan in Past 2013-2016 and Forecasting of New Vision 2030 at Ministry of Health in Saudi Arabia. J Pharm Pract Community Med. 2018;4(2):93-101.

Cite this article as: Alomi YA, Fallatah AO, Qahtani AAAL, Al-Shubbar N, Al-Yahya MF, Al-Smail EH. Cost of Total Parenteral Nutrition Services at the Ministry of Health, Saudi Arabia. Int J Pharmacol. Clin. Sci. 2019;8(1):39-44. 